Departamento de Anatomia Patológica Diretor: Prof. Dr. Altino A. A. Antunes

\title{
NECROSE AGUDA DO PÂNCREAS EM CÃO
}

\author{
Rubens Escobar Pires \\ Assistente \\ 2 estampas (4 figuras)
}

Conquanto relativamente frequente no homem, constituindo afecção de acentuada gravidade, é a necrose aguda do pâncreas, um achado raro nos animais domésticos.

No homem, a necrose aguda do pâncreas, em seu quadro mais agudo, se apresenta clinicamente com sintomas abrutos e sombrios que soem aparecer no chamado "drama abdominal".

Êsses sintomas variam com a extensão das lesões e se exteriorizam como uma peritonite super-aguda, com manifestações gerais graves, de choque. Nos casos de lesões pouco extensas, a afecção se localiza, havendo mesmo cura por cicatrização.

Nos animais domésticos, poucos são os trabalhos publicados, embora as pesquisas tenham sido feitas especialmente em cães e nossos conhecimentos sôbre o assunto decorrem não só dos estudos anátomoclínicos feitos no homem como das experiências, especialmente no terreno químico, últimamente palmilhado.

A casuística veterinária é escassa tendo sido porém verificada a afecção em equino (MARCATo) e em cão (FEDrigo). Nos matadouros se encontra frequentemente um processo de necrose do tecido gorduroso, principalmente em animais de engorda, sem que, na aparência, se verifique lesão do pâncreas. Os animais conservam boa saúde e o processo se distribue por todo o tecido adiposo. Não devemos confundir ambas as entidades nosológicas pelo menos no que respeita à patogenia e etiologia, havendo apenas de comum a necrose do tecido gorduroso, essência do último processo e frequente, porém, nem sempre presente, no primeiro. Ao tratarmos da morfologia macro e microscópica da necrose aguda do pâncreas daremos os caractéres diferenciais de ambas as afecções.

O pâncreas, em geral, se apresenta aumentado de volume e com zonas de côr acinzentada ou amarelada contrastando com a côr branco nacarada do órgão normal. Ao corte, o tecido pancreático mostra consistência mole e, nos casos mais adiantados, todo o órgão pode estar transformado em papa sanguinolenta.

Ao exame histológico, verificamos uma necrose mais ou menos extensa tanto do parênquima glandular como também do estroma, atin- 
gindo a parede dos vasos e ductos glandulares. Observam-se frequentemente hemorragias difusas no tecido, resultando daí o nome geralmente dado ao processo - "Pancreatite hemorrágica". Podem ser encontradas tromboses dos vasos pancreáticos, responsáveis por zonas secundárias de necrose. A necrose é de coliquação, mostrando-se o tecido corado em róseo na coloração pela hematoxilina-eosina.

O parênquima glandular encontra-se profundamente alterado. As células se transformam em massa grosseira rósea com poeira basófila correspondente aos restos dos núcleos destruidos. No tecido conjuntivo intersticial adiposo também atingido pelo processo, vamos verificar, de permeio com as massas necrosadas, deposição de cristais de ácidos graxos em forma de agulhas juxtapostas umas às outras e que, na coloração pela hematoxilina-eosina, se dissolvem nos fixadores comuns, restando porém as imagens negativas. Ao redor dessas deposições, a massa necrosada se tinge em roxo, evidenciando a presença de sais de cálcio. Nas zonas mais antigas, nota-se infiltração por grande quantidade de elementos figurados especialmente leucocitos e formação de nódulo granulomatoso.

Êsses nódulos típicos que se espalham por todo o tecido adiposo pancreático, confluindo de modo a formar nódulos maiores, podem ser vistos disseminados nos tecidos vizinhos onde há gordura e daí o processo estender-se ao epiplon, mesentério e peritôneo.

$\mathrm{Na}$ esteatonecrose simples vamos encontrar as mesmas formações nodulares, em tudo idênticas às descritas, disseminadas por todo o tecido adiposo do animal. Nas inspecções de matadouro, êsses nódulos são bem evidentes, como pequenas manchas cinzentas localizadas no tecido adiposo, contrastando com a côr branca normal do tecido.

Vários têm sido os estudos anátomo-clínicos e diversas as pesquisas feitas em animais de laboratório no sentido de se elucidar a etiologia e patogenia da necrose aguda do pâncreas.

Dessas pesquisas pode-se concluir que a essência do processo se baseia no aparecimento, dentro do próprio pâncreas, da tripsina; o tripsinogeno que, sabemos, é ativado na luz intestinal pela enteroquinase, por circunstâncias outras, se transforma em tripsina dentro do pâncreas. O fermento então irá atacar a molécula proteica celular trazendo a sua demolição e consequentemente uma alteração profunda no tecido do órgão. O processo não atinge só o parênquina glandular, porém afeta os ductos glandulares, as paredes dos vasos sanguíneos e o tecido conjuntivo intersticial adiposo da glândula. Desorganizandose dessa maneira o órgão, verifica-se a passagem do suco pancreático para seus interstícios e para os tecidos vizinhos e também a possibilidade de cair na corrente circulatória indo produzir lesões em zonas 
distantes. Assim, os fermentos existentes no suco pancreático e, em especial a lipase, irão agir sôbre os tecidos vizinhos produzindo aquelas lesões características do processo, entre as quais se salienta a esteatonecrose. Graças ao último fermento, a gordura existente nos tecidos é desdobrada libertando ácidos graxos que se depositam em agulhas na massa necrosada. Êsses ácidos graxos têm grande afinidade pelos sais de cálcio, retirando-os do sangue e dando origem a sabões altamente tóxicos para o organismo.

Da formação de produtos de demolição da substância albuminóide e sua consequente penetração na corrente circulatória, resultam para o organismo fenômenos anafiláticos em tudo semelhantes áqueles produzidos experimentalmente e aos obtidos por vários autores entre os quais SILVESTRE que, introduzindo por via paraenteral, filtrado de suco pancreático, desencadeou o choque anafilático; em outras experiências, notou-se também o aparecimento do quadro anatômico da pancreatite hemorrágica.

O processo se agrava ainda com os produtos tóxicos resultantes da ação da lipase. Últimamente as pesquisas nêsse sentido evidenciaram o papel importante representado pela lipase no deflagrar do processo mórbido. A lipase cinde a gordura em glicerina e ácidos graxos e êsses combinando-se com o cálcio sanguíneo, agem como substância tóxica, podendo destruir o tecido pancreático. NAKAGawa, determinando a necrose pancreática em cães, notou o aumento da lipase no sôro sanguíneo, aumento êsse capaz de produzir a morte rápida do animal, quando atinge certas proporções.

E' ponto pacífico o valor primordial representado pela tripsina na necrose aguda do pâncreas. No que porém tem havido mais discussões é sôbre o modo pelo qual se dá tal aparecimento em lugar tão inusitado.

A ligadura do canal de Wirsung e consequente parada do fluxo pancreático, pode determinar necrose do órgão porém não desencadeia o quadro da pancreatite hemorrágica como têm verificado vários autores.

Na espécie humana, a necrose aguda do pâncreas ou pancreatite hemorrágica aparece muitas vezes associada à colelitiase e daí, alguns autores relacionarem-na com a bile, atribuindo-a a um obstáculo litiásico na ampola de Vater, onde o acúmulo de bile provocaria seu refluxo para dentro do canal de Wirsung, ativando o tripsinogeno no interior mesmo do pâncreas. O mesmo poderia acontecer nos casos de estenose intestinal; é interessante o caso de SABrazÉs, PARCElifr e BouNIN, de necrose aguda pancreática, em que o canal de Wirsung estava 
obstruido por um ascarídeo. Experimentalmente, pesquisadores conseguiram reproduzir a doença injetando bile no canal de Wirsung.

A penetração do líquido entérico no canal de Wirsung tem sido incriminada por muitos como causadora da ativação do tripsinogeno $e$ seria mesmo o mecanismo pelo qual se explicaria a relativa frequência da doença aliada às úlceras pépticas do estômago e duodeno, pois, nessas, as perturbações nos movimentos peristálticos do duodeno facilitariam a penetração. Apesar da grande frequência com que tais distúrbios se verificam nas mais variadas moléstias do aparelho digestivo, não vemos a pancreatite hemorrágica acompanhar tão a miúdo tais processos.

Conquanto ainda não haja acôrdo sôbre o mecanismo da ativação do tripsinogeno dentro do pâncreas podemos desde já anotar vários fatores etiológicos como possíveis determinadores do desencadeamento do processo.

Dêles os que mais se salientam são os processos mórbidos que ocorrem no aparelho digestivo. As úlceras pépticas gástricas ou duodenais são frequentemente acompanhadas de sintomas que evidenciam comprometimento funcional do pâncreas. Tais como falta de digestão das gorduras, glicosúria transitória, perda de apetite alternada com fome voraz e muitos outros. Isso pode ser explicado pela contiguidade dos órgãos, podendo um processo flogístico, através das paredes, atingir o pâncreas; também a associação funcional é de tal modo íntima que um distúrbio de um órgão pode refletir-se imediatamente sôbre outro. Devemos também levar em consideração uma provável infecção canalicular ascendente, uma metástase hematógena, uma passagem direta por via linfática (demonstrada por BARTELs) e, em certos casos, não é de se negar importância aos fenômenos alérgicos determinados pela úlcera péptica. Os processos hepáticos e principalmente a litiase da vias biliares, estão associados frequentemente à necrose aguda do pâncreas como foi notado acima.

Outros fatores etiológicos podem se originar em perturbações circulatórias do órgão especialmente nas tromboses e embolias dos vasos pancreáticos determinando necroses mais ou menos extensas.

Em agosto de 1938, tivemos ocasião de proceder à necroscopia de um cão procedente do Depósito Municipal, falecido repentinamente após ligeiras convulsões. Nada havia sido notado de anormal $\mathrm{em}$ seu estado anterior a não ser certo grau de abstenção de alimentos e lassidão de movimentos.

Era um cão de raça mal definida, de talhe médio, desnutrido, com pequena quantidade de panículo adiposo. A necroscopia efetuada logo após a morte nada revelou digno de nota para o lado do tórax e de seus órgãos que estavam normais. A abertura da cavidade abdominal, notava-se desde logo a presença de mais ou 
menos $170 \mathrm{~cm}^{3}$ de líquido sero-sanguinolento. Na superfície parietal do peritôneo, nada digno de nota foi encontrado, não acontecendo o mesmo no mesentério e especialmente no epiplon e mesoduodeno, onde se verificavam inúmeras manchas esbranquiçadas, arredondadas, de tamanho variado, porém nunca ultrapassando $3 \mathrm{~mm}$ de diâmetro e dando a impressão de serem superficiais. Eram ligeiramente salientes, havendo em alguns lugares tendência a se fundirem, sendo mais numerosas nas proximidades do pânereas. O fígado, baço e rins apresentavam-se pràticamente normais.

A cauda do pâncreas era normal, não acontecendo porém o mesmo ao corpo em cuja parte juxtaposta ao duodeno se notava um aumento de espessura e coloração vermelho-escura. Êsse processo não só apanhava a zona pancreática em questão como também o duodeno, formando assim uma mancha vermelho-escura sem limites nítidos. Tinha-se a impressão de ter o processo que atingiu o órgão, provindo da parede duodenal suprajacente onde a infiltração sanguinolenta era mais intensa. As manchas esbranquiçadas já descritas tornavam-se mais numerosas ao redor do processo pancreático.

Pela abertura do tubo digestivo, verificou-se que o estômago apresentava caractéres normais, mas, na parte posterior da primeira porção do duodeno havia uma úlcera de bordos irregulares, cortantes, com o maior diâmetro situado transversalmente, medindo $3 \mathrm{~cm}$ por $1 \mathrm{~cm}$ de largura e com o fundo constituido por tecido mortificado de côr de sangue pisado.

O duodeno continha pouco material e êsse principalmente constituido por muco sanguinolento. $O$ intestino restante nada apresentava digno de nota.

\section{EXAMe histológico: - Duodeno: - Os cortes do órgão foram feitos no sentido transversal.}

A mucosa apresenta suas vilosidades bem como os ductos glandulares normais. Nota-se ligeira hiperemia dos pequenos vasos. As outras túnicas se apresentam normais porém com discreta hiperemia, já referida na mucosa. Em determinado ponto, a mucosa duodenal sofreu uma solução de continuidade apresentando desta maneira uma úlcera cujos bordos talhados a pique são constituidos pela mucosa que permaneceu e que se encontra infiltrada por elementos inflamatórios parvicelulares. $\mathrm{O}$ assoalho da úlcera é formado por massa necrótica grosseiramente homogênea. Logo abaixo dessa massa necrótica, distinguem-se as outras túnicas do duodeno tendo, porém, sofrido já o mesmo processo necrótico, notando-se mesmo em determinado ponto, que o processo atinge as camadas mais profundas de modo a interessar a própria serosa. Foram verificadas hemorragias extensas através do tecido alterado. Não se nota, senão discretamente em certos lugares, infiltração de elementos figurados inflamatórios.

Pâncreas: - 0 pâncreas apresenta-se com caracteres histológicos normais o mesmo não acontecendo, porém, nos lugares onde o órgão entra em contacto com o duodeno, próximo à úlcera já descrita. Nêsse lugar, os lóbulos glandulares encontram-se dissociados por hemorragia extensa que infiltrou profundamente o parênquima, seguindo o trajeto dos espaços adiposo-conjuntivos. Justamente abaixo da úlcera, nota-se um processo necrótico extenso atingindo os lóbulos glandulares e o tecido adiposo-conjuntivo. Nessa extensa zona necrosada havia hemorragias e também nódulos pequenos que se coravam intensamente pela hematoxilina, contrastando assim com o resto da necrose. Êsses nódulos são grosseiramente homogêneos, tendo o centro formado por massa fenestrada por pequenas falhas fusiformes e dispostas umas ao lado das outras, não obedecendo, no entanto, 
a uma sistematização. Essas formações nodulares estavam disseminadas por todo o tecido adiposo peripancreático bem como por todo o tecido adiposo do mesentério e epiplon, havendo ao redor dos nódulos infiltração leucocitária intensa.

DIAGNóstico an Átomo-Patológico: - Necrose aguda do pânereas (Pancreatite hemorrágica) originada pela contiguidade de uma úlcera péptica do duodeno.

Em nosso caso foi fácil reconstituir, pelos resultados necroscópicos e exame histológico, toda a história, etiologia e patogenia da necrose aguda pancreática que vitimou o animal.

A íntima relação do pâncreas com a porção duodenal ulcerada e a penetração da úlcera até suas camadas mais profundas facilitaram a passagem, por contiguidade, de elementos tóxicos produzidos pela necrose do assoalho da úlcera ou pelo próprio suco duodenal contendo a enteroquinase ativadora do tripsinogeno, desencadeando-se o processo de pancreatite hemorrágica com todo seu cortejo de lesões.

Julgamos o caso em apreço digno de relato pela raridade com que se apresenta nos animais domésticos e por elucidar, até certo ponto, o mecanismo da afecção.

\section{RESUMO}

A necrose aguda do pâncreas (Pancreatite hemorrágica) é afecção relativamente frequente no homem, porém constitui raridade entre os animais domésticos, sendo a casuística veterinária escassa no assunto.

O processo é deflagrado pela ativação do tripsinogeno dentro do próprio pâncreas dando origem à formação da tripsina que vai demolir a molécula proteica do tecido levando-o à necrose. A lipase do suco pancreático, infiltrando o tecido adiposo intra e peripancreático, desdobra a gordura em ácidos graxos e glicerina. Os ácidos graxos combinados com sais de cálcio do sangue vão formar sabões. Êstes e os produtos da desintegração da albumina determinam fenômenos tóxicos podendo acarretar a morte rápida do animal.

No que se refere à etiologia, várias são as causas responsáveis pelo processo, sendo as mais importantes as afecções gastro-duodenais e especialmente as úlceras. As moléstias hepáticas e especialmente as colelitíases, são apontadas como outros tantos fatores etiológicos e assim também as tromboses e embolias dos vasos pancreáticos.

Encontram-se frequentemente em animais de engorda, lesões no tecido adiposo intra e peripancreático semelhantes aos achados na necrose aguda cuja patogenia e etiologia porém são diferentes.

O caso apresentado refere-se a um cão, onde houve necrose aguda do pâncreas originada pela contiguidade de úlcera péptica duodenal. 


\section{SUMMARY}

The acute necrosis of the pancreas (Acute Hæmorrhagic Pancreatitis) is a disease which occurs frequently in man but rarely in domesticated animal, and the Veterinary casuistic on the subject is scanty.

The process develops when the trypsinogen is activated into the pancreas, giving origin to the trypsin. This enzyme attacks the proteic mollecule of the tissue producing necrosis. The lipase of the pancreatic juice infiltrates the intra - and peri - pancreatic adipose tissue and divides the fat into fatty acids and glycerin. The latter combines with calcium salts of the blood and give origin to soaps. All of these products are toxic to the body and may produce a quick death.

There are several etiologic factors responsible for the process, the important ones pertaining to the gastric and duodenal diseases, specially the ulcers. The hepatic diseases, the cholelithiasis chiefly and the thrombosis and embolies of pancreatic vessels are also among the etiologic factors.

A certain type of intra - and peri - pancreatic adipose tissue lesion similar to those found in acute necrosis of the pancreas, is found in fatty animals, but the pathogeny and etiology are different.

The author presents a case of acute necrosis of the pancreas originated by a duodenal peptic ulcer contiguity.

\section{BIBLIOGRAFIA}

Aschoff, L. - 1934 - Tratado de Anatomia Patológica 2: 971-972. Barcelona, Editorial Labor, S. A.

Castex, M. R. - Maggi, A. L. C. y Stocker, H. E. F. - 1942 - Pancreas: sus alteraciones funcionales en las úlceras duodenales. Arch. argent. enf. ap. digest., 17: 549-57.

Fedrigo, G. - 1940 - Di un caso di necrose pancreatica acuta rilevata in un cane. Nuova Veterinaria, $19(3): 66-71$.

Guibal, A. - Monnier, P. - Guibert, H. L. et Duc - 1938 - Un cas de necrose aiguë du pancréas. Ann. Anat. Path., 15 (3) : 249-262.

JoEst, E. - 1936 - Handbuch der speziellen patholischen Anatomie der Haustiere. 2: 340-345, 350. Berlin, Richard Schoetz.

Marcato, A. - 1939 - Necrosi acuta del pancreas nell'asino. Nuova Veterinaria, 17 (3): 86-90.

NAKAGAWA, Y. - 1941 - Studies on serum lipase and toxicity of the pancreas in experimentally induced acute pancreatic necrosis. Okayama-IgakkaiZasshi, 53: 1061 in J. A. M. A., 117 (17): 1474. 


\section{EXPLICAÇÃO DAS FIGURAS}

Fig. 1 - Mierofotografia da úlcera péptica do duodeno.

Fig. 2 - Microfotografia de tecido pancreático apresentando necrose do tecido glandular e do tecido intersticial.

Fig. 3 - Microfotografia de tecido pancreático com nódulos de esteatonecrose e infiltração leucocitária.

Fig. 4 - Microfotografia de um nódulo de esteatonecrose no epiplon, onde se vê no centro as fenestrações deixadas pelos cristais de ácidos graxos, dissolvidos, rodeados por uma zona de depósitos de sabões (em escuro) e infiltração leucocitária. 
Rubens Escobar Pires, Necrose aguda do pâncreas em cão
Rev. Fac. Med. Vet. S. Paulo, Vol. 2, fasc. s

Estampa $I$
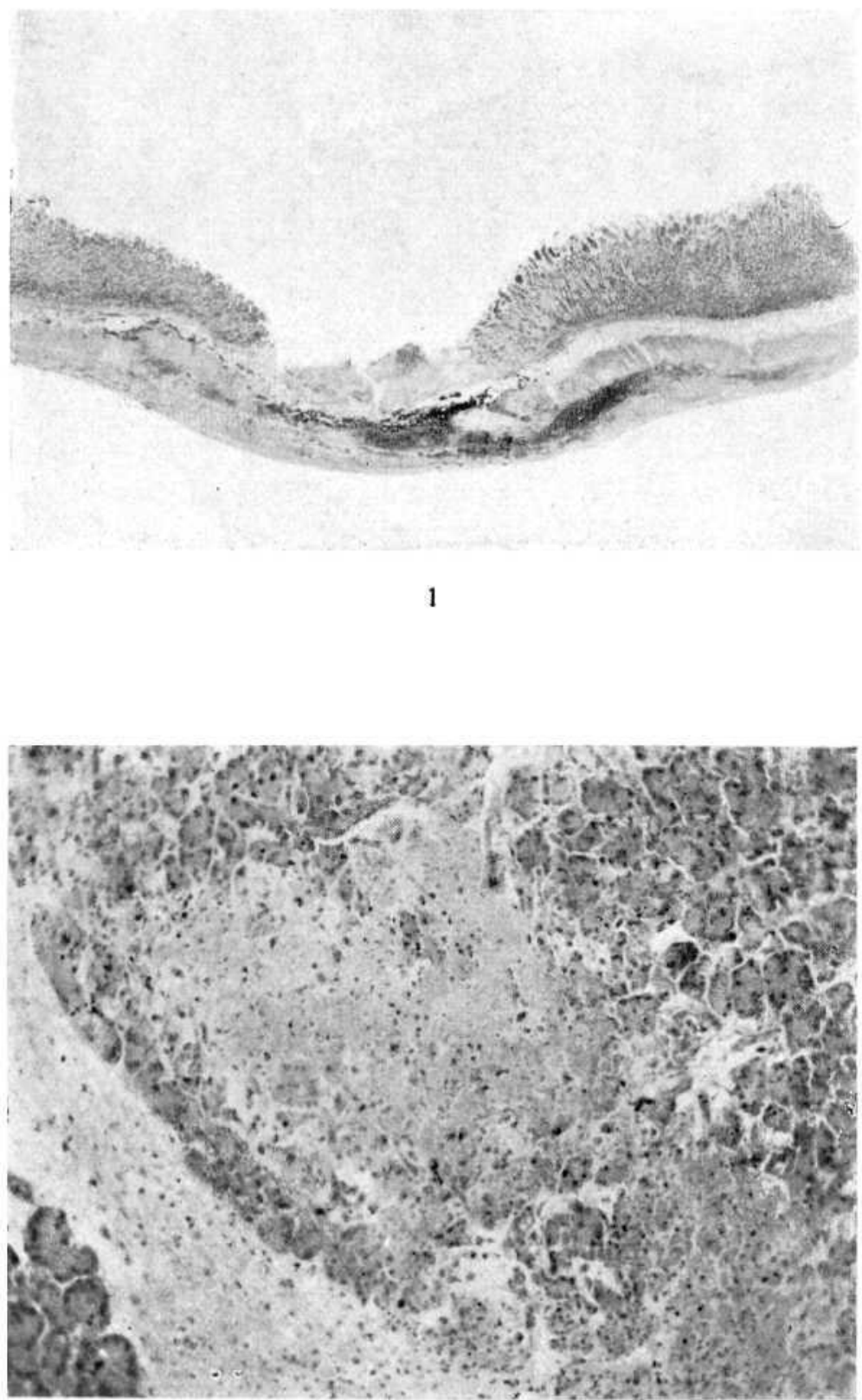
Rubens Escobar Pires, Necrose aguda do pâncreas em cāo
Rev, Fac, Mcd. Vet. S. Paulo, Vol, 2, fase, $s$

Estampa II
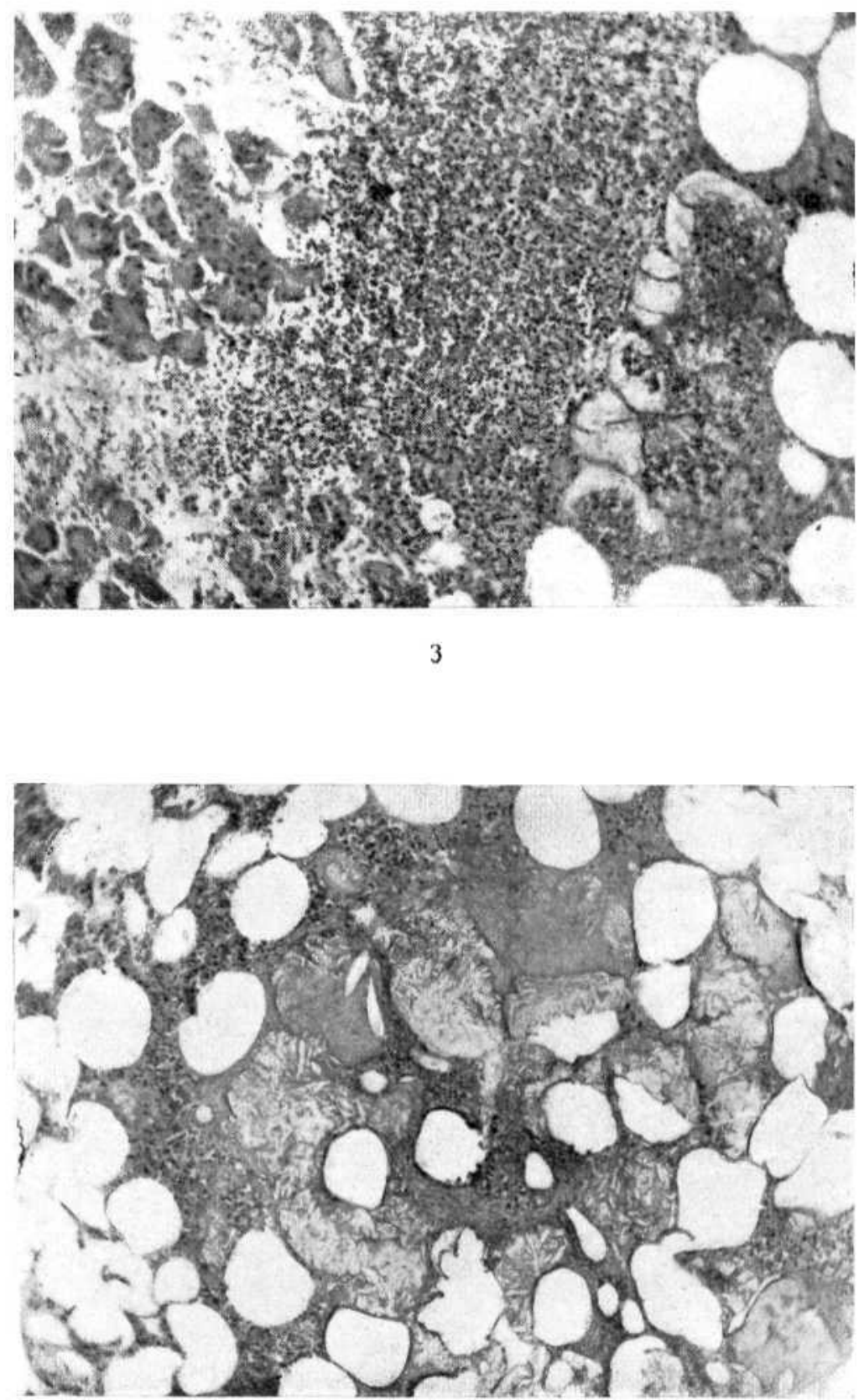